\title{
OPTIMALISASI STRATEGI OPERASI YANG EFEKTIF DAN EFISIEN PADA BISNIS PASTRY
}

\author{
Rizki Aina As Syahadat \\ Dosen Fakultas Prodi Teknik Industri Teknik Universitas Pamulang \\ Dosen00916@unpam.ac.id
}

\begin{abstract}
ABSTRAK
Optimalisasi strategi operasi yang efektif dan efisien pada bisnis pastry dimana terdapat faktor politik/legal, ekonomi, sosial, budaya, demografis, teknologi, dan kompetisi yang merepresentasikan evaluasi faktor ekternal perusahaan saat ini. Penggunaan analisis Five Force's menghasilkan 5 kekuatan antara lain Potential Entry of New Competitors dengan hasil High, Potential Development of Substitute Productsdengan hasil None, Bargaining Power of Suppliers dengan hasil Medium, Bargaining Power of Consumers dengan hasil Medium, Rivalry Among Competing Firms dengan hasil Medium. Penggunaan analisis SWOT dengan hasil 2 strategi SO, 2 strategi WO, 2 strategi ST, dan 1 strategi WT. Serta analisa faktor digunakan untuk menganalisa kondisi operasional perusahaan.
\end{abstract}

Kata kunci: Optimalisasi, Strategi operasi, Pastry, Five Force's

\section{PENDAHULUAN}

Permasalahan usaha kecil danmenengah (UKM) diIndonesia pada umumnya relatif sama, namun penentuan strategi untuk peningkatan daya saing tetap harus meneliti UKM secara detail dan berkesinambungan agar tercipta suatu solusi dalam memenangkan persaingan yang ada. Menurut European Commission, daya saing diartikan sebagai kemampuan menghasilkan produk barang dan jasa yang memenuhi pengujian internasional dan dalam saat bersamaan juga dapat memelihara tingkat pendapatan yang tinggi dan berkelanjutan (Meliala et al.2014)

Tantangan yang harus dihadapi untuk tetap eksis adalah memaksimalkan sistem dan budaya perusahaan kearah lebih baik, khususnya pada manajemen operasi. Manajemen Operasi merupakan kegiatan untuk mengatur dan mengelola secara optimal atas sumber daya (resource) yang tersedia dalam suatu proses transformasi, sehingga menjadi output yang memiliki manfaat lebih dari sebelumnya (Danang,2010:2) Karena perannya itu, Manajemen Operasi yang efektif dan efisien dipandang sangat perlu dalam mencapai tujuan perusahaan secara keseluruhan.
PT. XYZ didirikan pada tahun 2001. Perusahaan ini merupakan perusahaan perdagangan makanan berskala menengah yang pada saat ini sedang berkembang. PT. XYZ merupakan perusahaan yang berbasis industry Pastry.

PT. XYZ masih memiliki sistem manajemen yang sangat sederhana. Setiap kegiatan manajemen perusahaan (operasional , keuangan, SDM dan pemasaran) tidak dijalankan dengan profesional. $\mathrm{Hal}$ ini dikatakan tidak professional karena setiap kegiatan manajemen ini hanya dilakukan sebatas tugas-tugas administrasi dan pencatatan. Dengan demikian, PT. XYZ tidak menyelaraskan kegiatan bisnis perusahaannya dengan kebutuhan pasar yang dilayaninya, dan juga dengan tanpa memperhatikan sumber daya yang dimilikinya.

Hal tersebut terjadi dengan manajemen operasionalnya, dimana PT. XYZ tidak memiliki manajemen operasi yang efektif dan efisien, berikut adalah rumusan masalah dari tesis ini:

a. Bagaimana kondisi strategi operasi yang tepat dari segi kapabilitas operasional,kondisi pasar danstrategi bisnis perusahaan saat ini?

b. Faktor-faktor apa saja yang diperlukan dalam pengembangan strategi operasi 
perusahaan dari sisi manajemen operasi?

\section{DASAR TEORI}

\section{A. Pengertian Optimalisasi}

Optimalisasi adalah hasil yang dicapai sesuai dengan keinginan, jadi optimalisasi merupakan pencapaian hasil sesuai harapan secara efektif dan efisien. Menurut Kamus Besar Bahasa Indonesia Depdikbud (1998) optimalisasi berasal dari kata optimal yang berarti terbaik, tertinggi.

Optimalisasi banyak juga diartikan sebagai ukuran dimana semua kebutuhan dapat dipenuhi dari kegiatan-kegiatan yang dilaksanakan. Menurut Winardi (1996) optimalisasi adalah ukuran yang menyebabkan tercapainya tujuan. Secara umum optimalisasi adalah pencarian nilai terbaik dari yang tersedia dari beberapa fungsi yang diberikan pada suatu konteks.

\section{B. Konsep Industri}

Berikut ini adalah gambaran dari beberapa pendapat tentang definisi industri skala mikro, kecil, menengah, dan besar. Tabel 3.1 menunjukan definisi industri yang berasal dari dalam negeri.

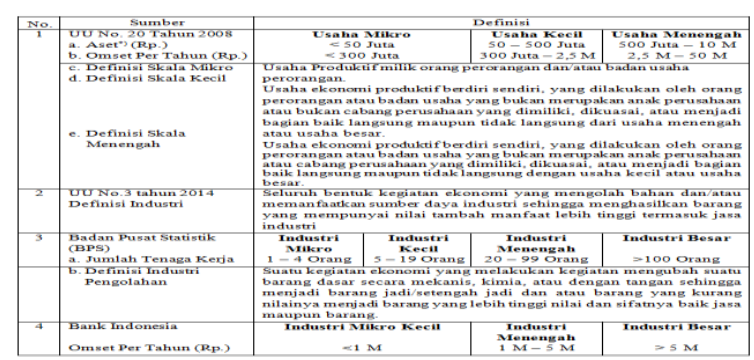

Sumber: Dari Berbagai Sumber; ${ }^{*}$ Tidak termasuk tanah dan bangunan

\section{Sejarah Pastry}

Berawal dari salah satu budaya Mesir, dimana mereka mengolah tepung dan pasta air untuk membungkus daging yang dimasak agar dapat menyerap cairan. Pastry lalu berkembang di Timur Tengah dan dibawa ke Eropa oleh umat Islam di abad ke-7. Pada abad pertengahan, mulai dikenal puding dan pie. Baru setelah memasuki abad ke-17, mulai berkembang puff pastry dan flaky pastry.

Puff Pastry awalnya ditemukan oleh pastrycook magang asal Perancis bernama Claudius Gele pada tahun 1645. Pada akhir masa magangnya, Claudius ingin membuatkan seloyang roti lezat buatannya untuk ayahnya yang sedang sakit. Dengan mempergunakan panduan diet sang ayah yang terdiri dari air, tepung dan mentega, Claudius mengolah adonan, melipat dan memasukkan mentega ke dalam adonan. Ia lakukan berulang-ulang hingga mencapai sepuluh kali lipatan, hingga akhirnya ia masukkan adonan tersebut ke dalam loyang.

Pengertian pastry menurut Pengolahan kue dan roti dalam Sudewi dan Patriasih (2005) : "Pastry ialah adonan yang berlapislapis dengan mentega atau lemak agar memperoleh hasil berlapisan atau berlembaran". Gisslen (1994: 151) berpendapat bahwa : "adonan lembaran ialah adonan pastry yang digiling, dilipat dan dilapisi dengan mentega atau lemak agar memperoleh hasil berlapis, mengeripik karena sewaktu dalam pembakaran telah terjadi peragian dan pengembangan pada adonan tersebut oleh adanya panas, uap air dan mentega yang menguap". Bahanbahan yang digunakan dalam pembuatan produk pastry sama dengan bahan dalam pembuatan roti, tetapi lemak yang digunakan ialah butter corsvet/lemak pelapis (rollin fat) merupakan margarin khusus untuk menghasilkan adonan yang biasa dilipat, seperti puff pastry dan danish pastry.

\section{Konsep Manajemen Strategik}

Manajemen strategik adalah rangkaian dari keputusan manajerial dan tindakan untuk menentukan kinerja perusahaan, yang mencakup pengamatan lingkungan (eksternal dan internal), formulasi strategi (perencanaan strategik atau jangka panjang), implementasi strategi, serta evaluasi dan pengendalian. Oleh karena itu, manajemen strategik menekankan pada monitoring dan evaluasi peluang eksternal dan ancaman yang bisa menjadi kekuatan dan kelemahan perusahaan Wheelen dan Hunger (2012). Gambar 4 menunjukkan interaksi dari empat unsur dasar proses manajemen strategik. Setiap unsur dikembangkan menjadi suatu model 
perencanaan (Gambar 2.1) yang mengintroduksi apa yang harus dilakukan perusahaan berkaitan dengan proses manajemen strategik.

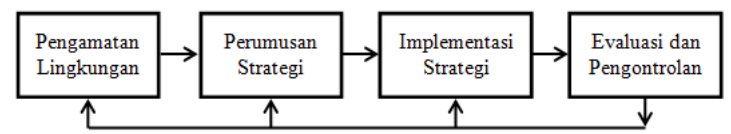

Gambar 2.1.Unsur Dasar Proses Manajemen Strategik

Sumber :Wheelen dan Hunger 2012

Model manajemen stratejik sesuai dengan yang dikemukakan oleh David (2009) dapat dilihat pada gambar 2.2.

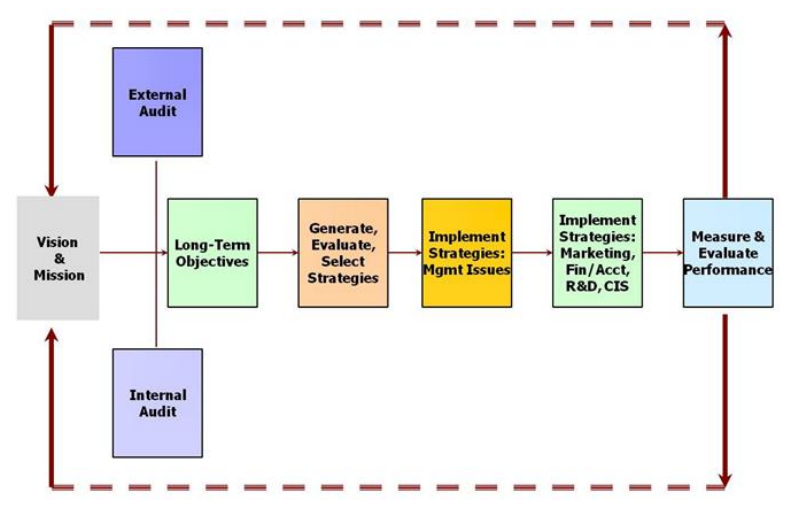

Gambar 2.2. Model Manajemen Stratejik Sumber :David

:StrategicManagement, ConceptandCases 12ed. 2009

\section{METODE PENGUKURAN DAN TEKNIK PENGUKURAN}

\section{A. Tahapan Penelitian}

Metodologi penelitian merupakan suatu langkah-langkah sistematis yang akan menjadi pedoman dalam menyelesaikan masalah.

Dengan melakukan metodologi penelitian ini, maka suatu penyelesaian masalah akan menjadi lebih terarah dan memberikan kemudahan dalam menganalisis masalah sampai kegiatan menyimpulkan semua permasalahan yang ada.

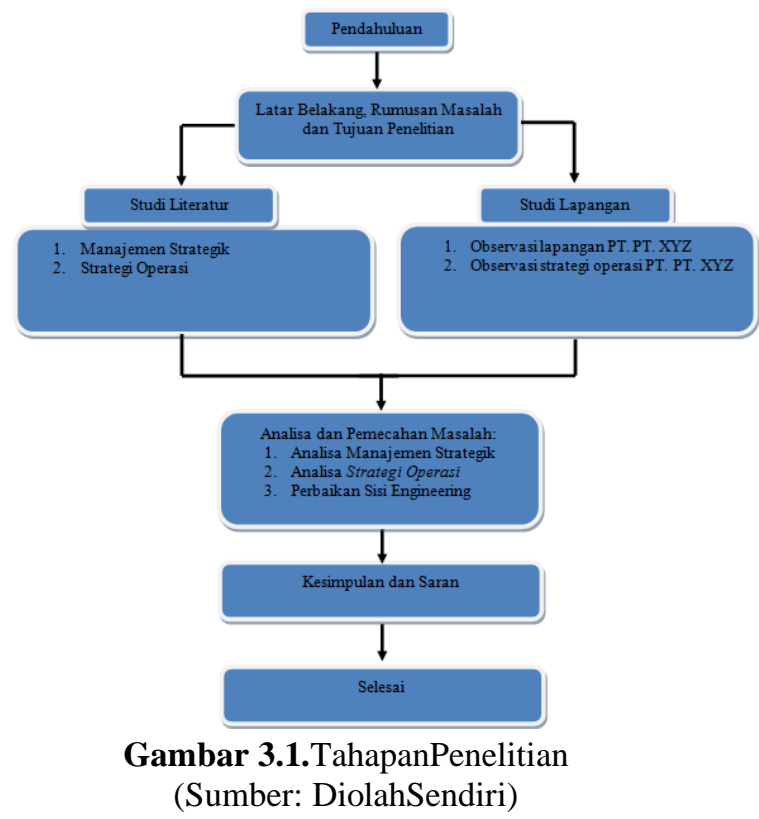

IV. HASIL DAN PEMBAHASAN

Pengumpulan data dilakukan untuk mengetahui optimalisasi strategi operasi yang efektif dan efisien pada bisnis pastry. Cara yang dilakukan adalah dengan melakukan penyebaran kuesioner dan wawancara terhadap para penghuni apartemen.

\section{External Factor Evaluation}

1. Faktor Politik dan Legal

Dalam kepentingan perizinan usaha, PT. XYZ telah memiliki perizinan dasar perusahaan antara lain:

a. Izin Mendirikan Bangunan (IMB) dari Badan Pelayanan Perizinan Terpadu (BP2T) Kota Tangerang Selatan

b. Izin Pemanfaatan Ruang (IPR) dari Badan Pelayanan Perizinan Terpadu (BP2T) Kota Tangerang Selatan

c. Surat Keterangan Domisili Usaha (SKDU) dari keluarah setempat

d. Izin Gangguan/HO dari Badan Pelayanan Perizinan Terpadu (BP2T) Kota Tangerang Selatan

e. Surat Izin Usaha Perdagangan (SIUP) dari Badan Pelayanan Perizinan Terpadu (BP2T) Kota Tangerang Selatan

f. Tanda Daftar Perusahaan (TDP) dari Badan Pelayanan Perizinan Terpadu (BP2T) Kota Tangerang Selatan

g. Tanda Daftar Bisnis dari Badan Pelayanan Perizinan Terpadu (BP2T) 
Kota Tangerang Selatan

h. SPP-IRT dari Dinas Kesehatan Kota Tangerang Selatan

2. Faktor Ekonomi

Kondisi perekonomian bangsa Indonesia tahun 2016 yang masih belum stabil akan memberikan dampak pada usaha ini. Apabila nilai tukar mata uang rupiah yang terdepresiasi terhadap dollar akan menyebabkan naiknya 444harga-harga produk di dalam negeri. Kenaikan harga ini akan mengakibatkan peningkatan biaya produksi yang pada akhirnya akan mempengaruhi harga produk. Namun, peningkatan ini tidak diimbangi dengan peningkatan daya beli masyarakat. Hal ini akan sangat mempengaruhi keberadaan usaha ini.

3. Faktor Sosial, Budaya, dan Demografi

Bisnis rumah tangga atau home industry merupakan suatu peluang usaha yang mulai bermunculan dalam era sekarang karena semakin sempitnya lapangan kerja yang tersedia. Bisnis semacam ini dapat dikelola di dalam rumah sehingga dapat dipantau setiap saat. Usaha kecil semacam ini dikelola oleh orang-orang yang memiliki hubungan kekerabatan. Modal yang dibutuhkan usaha ini sedikit dan alat-alat yang digunakan bersifat manual sampai dengan semi otomatis.

Pertumbuhan bisnis makanan dan minuman (food service) di Indonesia sangat pesat. Hal ini tidak terlepas dari gaya hidup masyarakat saat ini yang lebih memilih kafe atau restoran sebagai tempat untuk berkumpul bersama teman atau keluarga.

Bisnis Pastry merupakan bagian dari bisnis makanan jadi yang memanfaatkan tepung terigu sebagai bahan baku utama dalam proses produksinya. Roti yang semula dikenal sebagai makanan bule penjajah di Indonesia kini semakin populer dalam pola konsumsi pangan penduduk Indonesia, terutama golongan menengah ke atas. Kemudian berkembang menjadi pola makan masyarakat kota yang sibuk.

4. Faktor Teknologi

Peningkatan konsumsi roti oleh masyarakat Indonesia dalam beberapa tahun terakhir sangat dipengaruhi oleh kemajuan teknologi produksi roti. Secara konvensional, bisnis roti di Indonesia dilakukan oleh bisnis rumah tangga (usaha kecil) dan bisnis toko kue (Cake Outlet).

5. Faktor Kompetisi

Walaupun data-data yang telah disebutkan pada faktor-faktor sebelumnya menunjukkan bahwa Indonesia memberikan kesempatan yang luas bagi bisnis Pastry untuk berkembang, kesempatan luas ini juga memberikan iklim persaingan yang semakin sengit, khususnya untuk perusahaan-perusahaan yang bergerak dalam penjualan kue. Sengitnya iklim persaingan ini diakibatkan karena begitu banyaknya perusahaan-perusahaan Pastry yang juga memiliki model bisnis yang serupa.

\section{Porters Five Force's}

Berikut ini adalah hasil analisis Porters Five Forces:

1. Potential Entry of New Competitors dengan hasil High

2. Potential Development of Substitute Products dengan hasil None

3. Bargaining Power of Suppliers dengan hasil Medium

4. Bargaining Power of Consumers dengan hasil Medium

5. Rivalry Among Competing Firmsdengan hasil Medium

\section{SWOT}

Berikut ini adalah hasil analisis SWOT: Strategi SO

1. Menambah Loyal Customer dikarenakan sudah menjamurnya pecinta Pastry dan Bakery (S2, S3, O5, O6)

2. Mempertahankan kesederhanaan struktur organisasi dan menerapkan manajemen yang lebih teratur dan terarah terutama dari sisi operasional (S1, S4, S5, O1, O2, O4)

\section{$\underline{\text { Strategi }} \underline{\text { WO }}$}

1. Menerapkan manajemen yang lebih teratur dan terarah serta membangun standar operasional (W1, W2, W3, O5)

2. Menerapkan sistem pelaporan tiap departemen yang diatur langsung oleh perusahaan $(\mathrm{W} 4, \mathrm{~W} 5,01)$ 
Strategi ST

1. Mengatur sistem pengupahan yang sesuai dengan standar pemerintahan $(\mathrm{S} 1, \mathrm{~S} 4, \mathrm{~T}, 3)$

2. Mengatur program Local Store

Marketing lebih baik lagi (S2, S3, T1, T4, T5)

Strategi WT

Membuat program training untuk Manager tentang strategi operasi (W2, W3, W4, W5, T3)

\section{KESIMPULAN DAN SARAN}

\section{A. Kesimpulan}

Berdasarkan hasil pembahasan mengenai kapabilitas operasional, kondisi pasar danstrategi bisnis perusahaan saat ini untuk menentukan strategi operasi yang tepat adalah:

1. Kapabilitas Operasional

a) Speed

Perusahaan telah memiliki Call

Centre untuk merespon cepat

konsumen via komunikasi telepon dan memiliki Website serta sosial media untuk berinteraksi dengan konsumen terkait kepentingan promosi dan mengumpulkan ide-ide kreatif dari konsumen untuk dikembangkan di internal perusahaan.

b) Consistency

Perusahaan menggunakan mesin dan peralatan modern untuk menghasilkan pruduk yang konsisten agar konsumen terjamin pada saat membeli produk dari segi kualitas (ukuran, rasa, tekstur).

c) Acuity

Dalam hal ini perusahaan belum memiliki karyawan yang secara khusus bertugas untuk mengantisipasi persaingan bisnis sejenis, tetapi secara umum ada karyawan yang tugasnya mengelola website untuk melihat kondisi pasar.

d) Innovativeness

Perusahaan diwakili oleh departemen RND selalu mengikuti pameran tahunan yang berkaitan dengan bisnis pastry yang diselenggarakan di dalam maupun luar negri dalam rangka mendapatkan informasi trend produk pastry yang kemudian menjadi bahan perusahaan dalam rangka mengembangkan produk.

2. Kondisi Pasar \& Strategi Operasi

1) Kebutuhan Konsumen

Dengan menyesuaikan antara visi dan misi perusahaan, pengalaman perusahaan dalam menangani berbagai proyek serta evaluasi lingkungan eksternal pada analisis manajemen strategik, dapat disimpulkan bahwa karakteristik dan kebutuhan konsumen-konsumen PT. XYZ adalah sebagai berikut :

a) Konsumen adalah semua kalangan atau elemen masyarakat.

b) Konsumen membutuhkan cita rasa produk yang premium

c) Konsumen membutuhkan produk dengan harga terjangkau dengan rasa yang premium

2) Posisi Pasar

PT. XYZ memiliki strategi bisnis focus-low cost seperti yang telah dijelaskan pada bagian analisis manajemen strategik. Strategi bisnis demikian membidik pasar yang spesifik, karena diharapkan semua pangan olahan cokelat yang dibuat PT. XYZ dapat digemari oleh semua kalangan. Produk-produknya pada dasarnya memiliki pasar tersendiri disemua kalangan. Salah satu keunggulan dari produk PT. XYZ adalah Two Season, produk tersebut diunggulkan karena konsumen merasakan kue tersebut Full cokelat.

3) Aktifitas Kompetitor

Kompetitor PT. XYZ ratarata menjalankan model bisnis yang serupa dengan sedikit perbedaan. Perbedaan tersebut hanya merupakan perbedaan dari sisi produk yang dipasarkan. Dengan demikian, hampir setiap kompetitor tidak menjanjikan produk yang memiliki 
cita rasa sama dengan PT. XYZ.

Selain model bisnis,

kebanyakan dari kompetitor memiliki model kegiatan operasi yang sama. Setiap kegiatan bisnis dijalankan dengan manajemen sederhana.

Sudah ada beberapa kompetitor yang memiliki manajemen yang lengkap, mulai dari SDM, keuangan, pemasaran hingga operasional. Walaupun demikian, manajemen yang ada belum dapat menjalankan fungsinya selayaknya sebuah manajemen yang profesional.

Untuk kompetitor-kompetitor yang merupakan perusahaan besar, perusahaan-perusahaan ini rata-rata telah memiliki standar operasional yang jelas dan secara konsisten dijalankan. Perusahaan-perusahaan ini memiliki manajemen yang lebih profesional.

\section{4) Performance Objectives}

Sesuai dengan faktor-faktor yang telah dijelaskan mengenai kondisi dan kebutuhan pasar, maka sasaran performansi (performance objective) yang harus dicapai adalah sebagai berikut:

\section{a) Quality}

1. Kemampuan produksi yang tinggi yang mampu menghasilkan produk yang berkualitas dan konsisten.

2. Keramahan karyawan outlet dalam melayani konsumen.
3. Profesionalisme karyawan

4. Kemampuan karyawan untuk berkomunikasi dalam memberikan informasi

b) Speed

1. Melayani konsumen dengan tanggap, sigap, dan cepat.

2. Pengiriman produk ke outlet tepat waktu

3. Pengambilan keputusan yang cepat ketika terjadi permasalahan dari berbagai resiko yang muncul

c) Dependability

1. Konsumen selalu mendapatkan informasi tentang informasi pengembangan produk.

2. Ketepatan waktu pengiriman Delivery Order

d) Flexibility

1. Kemampuan untuk menyesuaikan dengan kondisi pada lingkungan bisnis

2. Fleksibilitas yang terkontrol dalam internal operasional

e) Cost

1. Penetapan harga Delivery Order sesuai dengan jarak

2. Penetapan harga produk yang disesuaikan dengan tingkat inflasi

2. Berdasarkan hasil pembahasan mengenai pengembangan strategi operasi perusahaan dari sisi manajemen operasi adalah:

\begin{tabular}{|c|l|l|l|}
\hline No & \multicolumn{1}{|c|}{ Standar } & \multicolumn{1}{c|}{ Kondisi Saat Ini } & \multicolumn{1}{|c|}{ Tindak lanjut } \\
\hline \multicolumn{3}{|c|}{ SISTEM PENGENDALIAN MANAJEMEN } \\
\hline 1 & $\begin{array}{l}\text { Terdapat struktur organisasi } \\
\text { yang jelas dalam perusahaan }\end{array}$ & $\begin{array}{l}\text { Struktur Organinisasi } \\
\text { Belum Jelas }\end{array}$ & $\begin{array}{l}\text { Membuat struktur } \\
\text { organisasi yang jelas }\end{array}$ \\
\hline $\begin{array}{l}\text { Setiap karyawan di dalam } \\
\text { perusahaan mengetahui } \\
\text { perencanaan strategi yang } \\
\text { ditetapkan sehingga dapat } \\
\text { bekerja sesuai dengan strategi } \\
\text { tersebut guna mencapai tujuan } \\
\text { perusahaan }\end{array}$ & $\begin{array}{l}\text { Tidak semua } \\
\text { karyawan mengetahui } \\
\text { perencanaan strategi } \\
\text { yang ditetapkan } \\
\text { perusahaan. }\end{array}$ & $\begin{array}{l}\text { Sosialisasi perencanaan } \\
\text { strategi perusahaan di } \\
\text { tingkat manajerial. }\end{array}$ \\
\hline 3 & $\begin{array}{l}\text { Prosedur kerja yang berlaku } \\
\text { di dalam perusahaan jelas dan } \\
\text { mudah dimengerti }\end{array}$ & $\begin{array}{l}\text { Belum semua } \\
\text { prosedur kerja dibuat } \\
\text { untuk semua } \\
\text { departemen }\end{array}$ & $\begin{array}{l}\text { Merancang prosedur } \\
\text { kerja untuk semua } \\
\text { departemen yang belum } \\
\text { memiliki prosedur }\end{array}$ \\
\hline 4 & Sistem pelaporan kinerja & Belum ada sistem & Merancang dan \\
\hline
\end{tabular}




\begin{tabular}{|c|c|c|c|}
\hline & $\begin{array}{l}\text { karyawan dilakukan secara } \\
\text { rutin setiap bulan }\end{array}$ & $\begin{array}{l}\text { pelaporan kinerja } \\
\text { karyawan }\end{array}$ & $\begin{array}{l}\text { mensosialisasikan } \\
\text { pelaporan kinerja } \\
\text { karyawan }\end{array}$ \\
\hline \multicolumn{4}{|c|}{ SISTEM PENGENDALIAN PPIC } \\
\hline 1 & $\begin{array}{l}\text { Karyawan PPIC memiliki } \\
\text { kompetensi yang sesuai dengan } \\
\text { bidangnya }\end{array}$ & $\begin{array}{l}\text { Belum ada karyawan } \\
\text { PPIC }\end{array}$ & $\begin{array}{l}\text { Membuat departemen } \\
\text { dan merekrut karyawan } \\
\text { PPIC }\end{array}$ \\
\hline 2 & $\begin{array}{l}\text { Jadwal induk produksi sudah } \\
\text { dibuat dengan baik dan benar }\end{array}$ & $\begin{array}{l}\text { Belum ada jadwal } \\
\text { induk produksi }\end{array}$ & $\begin{array}{l}\text { Dibuat setelah sudah } \\
\text { ada departemen dan } \\
\text { karyawan PPIC }\end{array}$ \\
\hline 3 & $\begin{array}{l}\text { Perencanaan jadwal induk } \\
\text { produksi sudah diterjemahkan } \\
\text { dalam Bill Of Material dengan } \\
\text { baik dan benar }\end{array}$ & $\begin{array}{l}\text { Belum ada jadwal } \\
\text { induk produksi yang } \\
\text { diterjemahkan } \\
\text { kedalam Bill Of } \\
\text { Material }\end{array}$ & $\begin{array}{l}\text { Dibuat setelah sudah } \\
\text { ada departemen dan } \\
\text { karyawan PPIC }\end{array}$ \\
\hline 4 & $\begin{array}{l}\text { Proses PPIC sudah berjalan } \\
\text { dengan baik dan benar }\end{array}$ & $\begin{array}{l}\text { Belum ada } \\
\text { departemen dan } \\
\text { karyawan PPIC }\end{array}$ & $\begin{array}{l}\text { Dapat terlihat setelah } \\
\text { sudah ada departemen } \\
\text { dan karyawan PPIC }\end{array}$ \\
\hline
\end{tabular}

\section{DAFTAR PUSTAKA}

Agustinus Wahyudi Sri, 1996. Manajemen Stratetejik. Jakarta: Binarupa Aksara.

A. Hitt, Michael, Ireland, R. Duane, E.Hoskisson, Robert, 2001. Manajemen Strategis, (terjemahan : Tim, Salemba Empat), Jakarta: Salemba Empat

Crown Dirgantoro, 2001. Manajemen Stratejik, Jakarta. Gasindo.

Danang \& Danang. 2010. Manajemen Operasional. Cet.1. CAPS, Yogyakarta

David, F.R. 2009. "Manajemen Strategis". Penerbit Salemba Empat, Jakarta.

E. Porter Michael, 1980, Competitive Strategy:Techniques for Analyzing Industries and Competitors, Ney York

E. Porter, Michael. 1994. Keunggulan Bersaing. (Terjemahan : Tim Binarupa Aksara)Jakarta: Binarupa Aksara.

Husain Umar, 2001. Strategic Manajemen In Action. Jakarta: PT. Gramedia Pustaka Utama.

http://humancapitaljournal.com/portersgeneric-strategies-memilih-rute-untukmeraih-keunggulan-kompetitif/

Rangkuti, Freddy, 2004, "Analisa SWOT Teknik Membedah Kasus Bisnis" PT. Gramedia Jakarta

Render, B. \& Heizer, J.2008. Operations Management Manajemen Operasi, Ed.7. Salemba Empat, Jakarta.
Siagian P Mpa, 2005 (Cetakan ke Desember) Manajemen Stratejik. Jakarta: Bumi Aksara.

Slack, Nigel. \& Lewis, Michael., 2002, Operations Strategy, Prentice Hall, London, UK

Supriyadi Edy, 2014, Perangkat Lunak Statistik SPSS + Amos Mengolah Data Untuk Penelitian-PenerbitIn Media, Jakarta 